\title{
EFEKTIVITAS DARK CHOCOLATE DAN WORTEL DALAM MENURUNKAN INTENSITAS DISMINOREA PRIMER
}

\author{
Rosvita Dewi Siregar ${ }^{1}$, Nora Veri $^{*}$, Meliani Sukmadewi Harahap ${ }^{3}$, Alchalidi $^{4}$, Nora Usrina ${ }^{5}$ \\ 1Puskesmas Manyak Payed, Aceh Tamiang, Aceh \\ 2,3,4Program Studi D-III Kebidanan Langsa Politeknik Kesehatan Kementerian Kesehatan Aceh \\ ${ }^{5}$ Politeknik Kesehatan Kementerian Kesehatan Aceh \\ *Korespondensi Email : nora.rahman1983@gmail.com
}

\section{ABTRACT EFFECTIVENESS OF DARK CHOCOLATE AND CARROTS IN REDUCING PRIMARY DISMINOREA INSTENSITIES}

Background: Dysminorrhea will get worse if accompanied by an unstable psychological condition. One of the causes of dysmenorrhea is hormonal factors where there is a hormonal imbalance. Pain during menstruation occurs due to high levels of prostaglandin hormones that make the uterine muscles contract. In Indonesia, the incidence of type dysmenorrhea primary is about $54.89 \%$ while the rest sufferers with secondary dysmenorrhea. Non-pharmacological therapy for dysmenorrhea is highly recommended, one of which are dark chocolate and carrots.

Purpose: To determine the effectiveness of the combination of dark chocholate and carrots in reducing the intensity of dysminorrhea.

Methods: This type of research uses a quasi-experimental design with a pretest-post-test control group design with a sample of 28 respondents experiencing primary dysmenorrhea. Pain intensity was measured by Numeric Rating Scale (NRS). Data collection was carried out during the pre-test, namely during menstruation in the first cycle and post-test data collection was carried out in the second cycle or after 30 days of treatment and assessed on the 31st day or the first menstruation in the following month. The statistical test used is Paired sample t-test.

Results: The administration of dark chocholate, carrots and a combination of the two was able to reduce the intensity of primary dysminorrhea with a glossy $p$-value $\leq 0.05$.

Conclusion: Consumption of dark chocholate, carrots and a combination of both can reduce the intensity of primary dysmenorrhea.

Suggestion for adolescents with primary dysmenorrhea to use non-pharmacologic therapy to reduce pain intensity such as carrots and dark chocholate in order to avoid the side effects of pharmacological drugs. Further research is needed in vitro on the mechanism of the combination of carrots and dark chocholate in reducing the intensity of dysmenorrhea

Keywords : Dark Chocholate, Carrot, Dysminorea Intensity, adolescents

\section{ABSTRAK}

Latar Belakang : Disminorea akan bertambah parah apabila disertai dengan kondisi psikis yang labil. Salah satu penyebab dismenorea adalah faktor hormonal dimana adanya ketidakseimbangan hormonal. Nyeri ketika menstruasi tersebut timbul akibat tingginya hormon prostaglandin yang membuat otot rahim berkontraksi. Di Indonesia angka kejadian dismenorea tipe primer adalah sekitar $54,89 \%$ sedangkan sisanya penderita dengan dismenorea sekunder. Terapi disminorea secara non farmakologi sangat diabjurkan salahs satunya adalah dark chocholate dan wortel.

Tujuan Penelitian : Untuk mengetahui efektivitas kombinasi dark chocholate dan wortel dalam menurunkan intensitas disminorea.

Metode Penelitian : Jenis penelitian ini menggunakan quasi eksperiment dengan desain pretest- post test control group design dengan sampel adalah responden yang mengalami disminorea primer sebanyak 28 orang. Intensitas nyeri diukur dengan Numeric Rating Scale (NRS). Pengambilan data dilakukan pada saat pre-test yaitu saat haid pada siklus pertama dan pengambilan data post-test dilakukan pada siklus kedua atau saat setelah dilakukannya perlakuan selama 30 hari dan dinilai pada hari ke 31 atau pertama haid di bulan berikutnya. Uji statistik yang digunakan adalah Paired sample t-tes.

Hasil Penelitian : Pemberian dark chocholate, wortel dan kombinasi keduanya mampu menurunkan 


\section{JKM (Jurnal Kebidanan Malahayati),Vol 7,No.4.Oktober 2021, ISSN (Print) 2476-8944 ISSN (Online) 2579-762X, Hal 642-646}

intensitas disminorea primer dengan nilap $p$-value $\leq 0,05$.

Kesimpulan : Pemberian dark chocholate, wortel dan kombinasi keduanya mampu menurunkan intensitas disminorea primer.

Sarankan pada remaja yang mengalami disminorea primer untuk menggunakan terapi non faramakologis untuk mengurangi intensitas nyeri seperti wortel dan dark chocholate agar terhindar dari efek samping obatobatan farmakologi. Diperlukan penelitian lebih lanjut secara in vitro tentang mekanisme kombinasi wortel dan dark chocholate dalam menurunkan intensitas disminorea.

Kata Kunci : Dark Chocholate, Wortel, Intensitas Disminorea, Remaja Putri

\section{PENDAHULUAN}

Permasalahan dismenorea adalah permasalahan yang sering dikeluhkan oleh wanita. Suatu studi menyatakan bahwa prevalensi remaja yang mengalami disminorea adalah sebesar $86 \%$ atau sebanyak 138 orang dari total 160 sampel dengan usia menarche paling muda 9 tahun dan usia menarche tertua adalah 17 tahun (Kusnaningsih, 2020). Berdasarkan data dari World Health Organization (WHO), prevalensi dismenorea sebesar 1.769 .425 jiwa (90\%). Di Indonesia angka kejadian dismenorea sebesar 107.673 jiwa $(64,25 \%)$, yang terdiri dari 59.671 jiwa $(54,89 \%)$ mengalami dismenorea primer dan 9.496 jiwa $(9,36 \%)$ yang mengalami dismenorea skunder.

Dismenorea adalah rasa sakit yang terjadi ketika mulai menstruasi yang dapat mengganggu aktivitas sehari-hari. Rasa sakit atau nyeri disminorea menyerupai kejang diperut bagian bawah yang dimulai 24 jam sebelum darah menstruasi keluar dan berlangsung sampai 12 jam pertama (Andarmoyo, 2013). Disminorea akan bertambah parah apabila disertai dengan kondisi psikis yang labil. Salah satu penyebab dismenorea adalah faktor hormonal dimana adanya ketidakseimbangan hormonal. Nyeri ketika menstruasi tersebut timbul akibat tingginya hormon prostaglandin yang membuat otot rahim berkontraksi (Misliani et al., 2019).

Manajemen nyeri ketika menstruasi dapat dilakukan dengan menggunakan metode farmakologis dan nonfarmakologis. Pengobatan farmakologi disminorea dapat menggunakan obat analgetika dan obat non-steroidanti inflamasi (NSAID) seperti asam mefenamat, ibuprofen, piroxicam dan lain sebagainya (Misliani et al., 2019). Sedangkan cara nonfarmakologis dapat dilakukan dengan kompres air hangat, kompres air dingin (Maimunah et al., 2017), hipnoterapi (Aprilyadi et al., 2018), terapi zink (Damayanti et al., 2020), endorphin massage (Septiani et al., 2021) dan lain sebagainya. Terapi disminorea secara non farmakologi juga dilakukan dengan mengkonsumsi beberapa jenis herbal seperti jahe merah (Mariza \&
Sunarsih, 2019), air kelapa hijau, (Rismaya et al., 2020), kunyit asam (Baiti et al., 2019), kombinasi jahe dengan dark chocholate (Faizah \& Mukhoirotin, 2020) dan air rebusan wortel (Vidayati \& Munawaroh, 2019). Dalam penelitian ini penulis mengkombinasikan antara wortel dengan dark chocolate dalam mengurangi intensitas disminorea pada remaja putri. Dark chocolate mengandung kalsium, kalium, natrium, magnesium serta vitamin A, B1, C, D dan E. Sedangkan wortel mengandung mengandung banyak vitamin $A, B, C, D, E$ dan $K$.

\section{METODELOGI PENELITIAN}

Jenis penelitian ini menggunakan quasi eksperiment dengan desain pretest- post test control group design, untuk mengetahui efektifitas dark chocolate dan wortel (Daucus Carota) terhadap intensitas dismenorea pada mahasiswi di Prodi D-III Kebidanan Langsa Poltekkes Kemenkes Aceh. Pengambilan data dilakukan pada saat pretest yaitu saat haid pada siklus pertama dan pengambilan data post-test dilakukan pada siklus kedua atau saat setelah dilakukannya perlakuan selama 30 hari dan dinilai pada hari ke 31 atau pertama haid di bulan berikutnya.

Nyeri disminorea diukur setelah diberikan dark chocholatte dan jus wortel dalam 2 siklus pada bulan pertama dan bulan berikutnya dengan menggunakan skala nyeri Numeric Rating Scale (NRS) dengan nilai 0-10. Dark chocholate diberikan sebanyak $40 \mathrm{gram} /$ hari dilarutkan dengan $200 \mathrm{cc}$ air putih hangat, selama 30 hari dikonsumsi $1 \mathrm{x}$ sehari pada pagi hari secara oral. Jus wortel sebanyak 250 gram / hari diblender dengan $200 \mathrm{cc}$ air putih. Diberikan selama 30 hari, setiap pagi sebanyak 1 kali / hari secara oral. Kombinasi jus wortel dan dark chocholate 40 gram/hari dicampur 250 gram/hari wortel diblender dengan $200 \mathrm{cc}$ air putih selama 30 hari dikonsumsi 1 x sehari pada pagi hari secara oral. Proses kontrolling agar responden mengkonsumsi dark chocholate dan jus wortel adalah responden mengirimkan video ketika mengkonsumsi ke grup WhatsApp (WA). 
Populasi pada penelitian ini adalah seluruh mahasiswi D-III tingkat 2 Prodi Kebidanan Langsa Poltekkes Kemenkes Aceh yang mengalami Dismenorea Primer yaitu sebanyak 28 orang. Teknik pengambilan sampel adalah dengan teknik purposive sampling dimana responden dipilih hanya yang mengalami disminorea ringan dan sedang pada saat pretest awal, tidak mengkonsumsi obatobatan dan bersedia mengkonsumsi jus wortel dan dark chocholatte. Responden yang lupa minum jus atau dark chocholate akan dieksklusi dari penelitian.

\section{HASIL DAN PEMBAHASAN}

Penelitian ini telah dilaksanakan pada tanggal 28 Mei s/d 08 Juli 2019 pada 24 mahasisiwi Prodi D-III Kebidanan Langsa Poltekkes Kemenkes Aceh, dengan hasil penelitian sebagai berikut
Tabel 1.

Karakteristik Responden Berdasarkan Umur

\begin{tabular}{|c|c|c|}
\hline Umur & $F$ & $\%$ \\
\hline 18 Tahun & 13 & 54,2 \\
\hline 19 Tahun & 8 & 33,3 \\
\hline 20 Tahun & 3 & 15,5 \\
\hline Total & 24 & 100 \\
\hline
\end{tabular}

Pada tabel diatas diketahui bahwa dari 24 $(100 \%)$ responden tingkat I, mayoritas mahasiswi berumur 18 tahun sebanyak 13 orang $(54,2 \%)$ dan minoritas mahasiswi yang berumur 20 tahun sebanyak 3 orang $(15,5 \%)$. Dalam penelitian ini untuk membandingkan rerata perbedaan intensitas dismenorea pada data pre-test dan post-test masing-masing kelompok menggunakan Uji Paired sample $t$-tes. Disajikan pada tabel berikut :

Tabel 2.

Perbedaan Intensitas Dismenorea Pada Responden

\begin{tabular}{lccc}
\hline \multicolumn{1}{c}{ Kelompok } & $\begin{array}{c}\text { Pre-test } \\
\text { Rerata } \pm \text { Sd }\end{array}$ & $\begin{array}{c}\text { Post-test } \\
\text { Rerata } \pm \text { Sd }\end{array}$ & $\boldsymbol{P}_{\text {Value }}$ \\
\hline Kontrol & $4.67 \pm 1.633$ & $5.33 \pm 1.366$ & 0,025 \\
Dark Chocholate & $5.17 \pm 2.137$ & $1.83 \pm 1.169$ & 0,027 \\
Wortel & $4.83 \pm 1.941$ & $1.83 \pm 1.169$ & 0,000 \\
Dark Chocholate dan Wortel & $5.67 \pm 1.862$ & $1.50 \pm 1.049$ & 0,001 \\
\hline
\end{tabular}

Pada tabel diatas menunjukkan perbedaan rerata intensitas dismenorea pada kelompok kontrol saat pre-test $4.67 \pm 1.633$ dan post-test $5.33 \pm 1.366$ artinya terdapat peningkatan intensitas dismenorea setelah diberikan perlakuan air putih. Sedangkan pada kelompok perlakuan dark chocholate pada saat pre-test terdapat nilai rerata $5.17 \pm 2.137$ dan post-test $1.83 \pm 1.169$ artinya ada penurunan intensitas dismenorea setelah konsumsi coklat. Pada kelompok perlakuan wortel didapat perbedaan rerata intensitas dismenorea pada saat pre-test yaitu $4.83 \pm 1.941$ dan turun pada post-test menjadi $1.83 \pm 1.169$ artinya terjadi penurunan intensitas dismenorea setelah diberikan wortel. Selanjutnya intensitas dismenorea pada kelompok kombinasi dark chocholate dan wortel pada saat pre-test rerata $5.67 \pm 1.862$ dan post-test $1.50 \pm 1.049$ yang artinya ada penurunan intensitas dismenorea setelah diberikan coklat dan wortel.

Intensitas dismenorea sebelum dan sesudah intervensi pemberian dark chocholate, jus wortel dan kombinasi keduanya semua dengan nilai $p$ value $\leq 0,05$ yang berarti terdapat pengaruh pemberian dark chocolate dan wortel terhadap intensitas dismenorea primer.

\section{PEMBAHASAN}

Pada penelitian ini didapatkan hasil ada pengaruh pemberian dark chocolate terhadap intensitas dismenorea pada responden. Penelitian ini serupa dengan penelitian sebelumnya yang menyatakan bahwa pemberian cokelat hitam 100 gram $80 \%$ berpengaruh terhadap penurunan dismenorea primer (Wahtini et al., 2021). Penelitian ini juga sejalan dengan hasil penelitian yang menyatakan terdapat perbedaan yang bermakna antara pemberian coklat hitam sebanyak $40 \mathrm{gr} / \mathrm{hari}$ selama 3 hari dan jahe $40 \mathrm{gr} /$ hari selama 3 hari sebelum menstruasi terhadap penurunan nyeri menstruasi (Amelia \& Maharani, 2017). Pemberian dark chocholate yang berbentuk permen juga mampu menurunkan disminorea primer (Natalia \& Astikasari, 2019).

Dark chocholate mengandung senyawa yang berfungsi untuk mengurangi syaraf-syaraf yang tegang. Dark Chocolate mengandung magnesium yang berguna untuk merelasasi otot dan memberikan rasa rileks yang dapat mengendalikan hati yang murung selain itu magnesium juga berfungsi dilatasi pembulu darah. Kandungan lain 


\section{JKM (Jurnal Kebidanan Malahayati),Vol 7,No.4.Oktober 2021, \\ ISSN (Print) 2476-8944 ISSN (Online) 2579-762X, Hal 642-646}

dark chocholate adalah mineral dapat merangsang otak untuk melepaskan hormon endorphin. Endorphin merupakan subtansi yang dikeluaran oleh tubuh juga berfungsi untuk merelaksasi otototot dan merangsang otak untuk perlepasan hormon endorphin yang berfungsi menghambat nyeri menstruasi.

Pada hasil penelitian ini didapatkan hasil ada pengaruh pemberian Wortel (Daucus Carota) terhadap intensitas dismenorea pada responden. Penelitian ini sejalan dengan penelitian yang dilakukan Puspita (2018) yang menyatakan bahwa ada pengaruh pemberian jus wortel terhadap nyeri dismenorea setelah pemberian wortel sebanyak $250 \mathrm{gr} /$ hari selama 7 hari (Puspita, 2018). Penelitian ini juga sejalan dengan penelitian lain yang menyatakan pengaruh pemberian jus wortel dapat menurunkan derajat dismenorea (Sari \& llayati, 2020). Pemberian air perasaan wortel ada pengaruh terhadap penurunan intensitas dismenorea, dengan dosis yang diberikan sebanyak $250 \mathrm{gr} /$ hari dan air putih $100 \mathrm{cc}$ selama 7 hari (Hastuti et al., 2016; Vidayati \& Munawaroh, 2019).

Vitamin pada wortel bermanfaat untuk membantu memblokir formasi prostaglandin dan membantu mengatasi efek peningkatan hormon prostaglandin dimana peningkatan hormon prostaglandin dapat mempengaruhi terjadinya disminorea. Kandungan wortel yang berfungsi untuk mengurangi dismenorea yaitu, betakaroten, magnesium, serat, dan zat besi yang berfungsi untuk pencegahan peningkatan hormon prostaglandin, mengendalikan aliran darah, mengurangi rasa sakit atau nyeri, merelaksasi otot (Puspita, 2018).

Pada hasil penelitian ini didapatkan hasil ada pengaruh pemberian dark chocolate ditambah wortel terhadap intensitas dismenorea primer pada responden. Penelitian ini belum pernah diteliti oleh peneliti lain. Hal ini diduga terjadi karena kandungan yang ada didalam dark chocolate dan wortel (daucus carota) memiliki kesamaan dalam menurunkan intensitas dismenorea yaitu salah satunya adalah kandungan magnesium yang berfungsi memperbesar pembulu darah, merelaksasi otot-otot dan dapat memberikan rasa rileks, merangsang otak untuk perlepasan hormon endorphin yang berfungsi menghambat nyeri haid. Kombinasi zat gizi dan juga antioksidan dari kedua sumber tersebut bekerja secara bersama-sama untuk menurunkan intensitas disminorea.

\section{SIMPULAN}

Pemberian dark chocholate dan wortel mampu menurunkan intensitas disminorea primer pada remaja sehingga dapat dijadikan sebagai salah satu terapi non farmakologis dalam mengurangi disminorea.

\section{SARAN}

Diperlukan penelitian lebih lanjut secara in vitro tentang mekanisme kombinasi wortel dan dark chocholate dalam menurunkan intensitas disminorea.

\section{DAFTAR PUSTAKA}

Amelia, R., \& Maharani, S. I. (2017). Effectiveness of Dark Chocolate and Ginger on Pain Reduction Scale in Adolescent Dysmenorhea. Jurnal Kebidanan, 6(12), 73. https://doi.org/10.31983/jkb.v6i12.1915

Andarmoyo, S. (2013). Konsep \& Proses Keperawatan Nyeri. In Nyeri.

Aprilyadi, N., Feri, H. J., \& Ridawati, I. D. (2018). Efektifitas Hypnotherapi Terhadap Penurunan Nyeri Dismenorea Pada Siswi Sma. Jurnal Perawat Indonesia, 2(1), 10. https://doi.org/10.32584/jpi.v2i1.39

Baiti, C. N., Astriana, Evrianasari, N., \& Yuliasari, D. (2019). Kunyit asam mengurangi nyeri haid pada remaja putri.

Damayanti, N. K. S., Sunarsih, S., \& Utami, V. W. (2020). Terapi Zinc Dalam Menurunkan Nyeri Menstruasi (Dysmenorrhea). Jurnal Kebidanan Malahayati, 6(3), 394-400. https://doi.org/10.33024/jkm.v6i3.1687

Faizah, N., \& Mukhoirotin, M. (2020). Pengaruh Pemberian Cokelat Hitam (Dark Chocolate) Dan Jahe Terhadap Intensitas Nyeri Haid (Dysmenorrhea). Jurnal Keperawatan, 8(2), 43-49. https://doi.org/10.47560/kep.v8i2.128

Hastuti, P., Aini, F. N., Purwokerto, P. K., \& Semarang, P. K. (2016). Pengaruh Pemberian Air Perasan Wortel Terhadap Disminorea. Jurnal Riset Kesehatan, 5(2), 79-82.

Kusnaningsih, A. (2020). Prevalensi Dismenore pada Remaja Putri di Madrasah Aliyah Darul Ulum dan Miftahul Jannah Palangka Raya. Jurnal Surya Medika, 5(2), 1-8. https://doi.org/10.33084/jsm.v5i2.1247

Maimunah, S., Sari, R. D. P., \& Prabowo, A. Y. (2017). Perbandingan Efektivitas Kompres Hangat dan Kompres Dingin sebagai Terapi Non-Farmakologis Dismenore pada Remaja. Medula, 7(5), 79-83.

Mariza, A., \& Sunarsih, S. (2019). Manfaat Minuman Jahe Merah Dalam Mengurangi Dismenorea Primer. Jurnal Kebidanan Malahayati, $\quad$ 5(1), 39-42. 
https://doi.org/10.33024/jkm.v5i1.886

Misliani, A., Mahdalena, \& Syamsul, F. (2019). Penanganan Dismenore Cara Farmakologi dan Nonfarmakologi. Jurnal Citra Keperawatan, 7(1), 23-32.

Natalia, S., \& Astikasari, N. D. (2019). Pengaruh Permen Dark Chocolate terhadap Nyeri Dismenore Primer pada Remaja Putri di SMP Gaya Baru Desa Sumberejo Kecamatan Gedangan Kabupaten Malang. Journal for Quality in Women's Health, 2(2), 31-37. https://doi.org/10.30994/jgwh.v2i2.35

Puspita, N. L. M. (2018). The Influence Of Carrot Juice And Avocado Juice To Dysmenorrhoea Pain In Adolescent Girls. Jurnal IImiah Kebidanan, 4(1), 14-19.

Rismaya, I., Rosmiyati, R., \& Mariza, A. (2020). Pemberian Air Kelapa Hijau Dapat Menurunkan Dismenore. Jurnal Kebidanan Malahayati, $\quad 6(3), \quad 332-328$. https://doi.org/10.33024/jkm.v6i3.1764

Sari, H., \& llayati, E. (2020). Decreasing Dysmenorrhoea Pain Level by Giving Carrot Juice to Young Women. 6(November), 281284.

Septiani, H., Wulan, S., \& Dewi, R. (2021). Perbandingan Pengaruh Teknik Endorphine Massage Dengan Kompres Abstract Comparison Of The Effect Of Endorphine Massage Engineering With Warm. 7(2), 319323.

Vidayati, L. A., \& Munawaroh. (2019). Pengaruh Pemberian Air Perasan Wortel Terhadap. Prosiding Seminar Nasional Poltekkes Karya Husada Yogyakarta, 1(1), 2686-5521.

Wahtini, S., Hidayah, F., \& Wahyuntari, E. (2021). Coklat hitam menurunkan nyeri dismenore. Biomedika, 13(1), 28-35. https://doi.org/10.23917/biomedika.v13i1.108 27 